small meals (owing to distortion of the stomach and cardio-oesophageal junction); and (5) an abdominal fluid thrill but no shifting dullness, indicating a localised collection of fluid and clotted blood.

The likely pathogenesis of the haemorrhage is over-distension of the stomach with tearing of a small blood vessel in the lesser omentum. The blood tracks inferiorly, stripping peritoneum from the posterior wall of the stomach, into the greater omentum. Our case shows that if the condition is promptly recognised good results may be achieved with early transfusion of adequate quantities of blood and antihaemophilic globulin and without surgical intervention.

We thank Dr Alison Craig, Mr A Stizovich, and Mr K Kutik for help with translations.

1 Mersten, A, et al, Ceskoslovenska Gastroenterologie a Vyziva, 1975, 29, 406.

2 Felson, B, fournal of the American Medical Association, 1974, 4, 230.

${ }^{3}$ Wright, F W, et al, Radiology, 1971, 98, 571.

(Accepted 9 fuly 1979)

King's College Hospital, Denmark Hill, London SE5 8LS

M I ADELMAN, MB, senior registrar (present address : Lewisham Hospital, London SE13 6LH)

PHILIP GISHEN, DMRD, FRCS, consultant radiologist

$P$ DUBBINS, BSC, FRCR, senior registrar in radiology

R S MIBASHAN, MD, FRCP, consultant haematologist

\section{Spontaneous recovery from rapidly progressive glomerulonephritis}

Idiopathic rapidly progressive glomerulonephritis is characterised by crescent formation and rapid deterioration of renal function. Most patients require haemodialysis, since treatment with anticoagulants, steroids, and cytotoxic agents has little apparent effect. ${ }^{1}$ Plasmapheresis may be of value in some patients with Goodpasture's syndrome," but the reports have not been universally favourable. ${ }^{3}$ Bolton and Couser recently reported on nine patients with the condition, six of whom appeared to benefit dramatically from intravenous pulse methylprednisolone followed by oral steroids. ${ }^{4}$ We describe three patients with idiopathic rapidly progressive glomerulonephritis who required haemodialysis but thereafter recovered without any specific treatment.

\section{Case reports}

Case 1-A 60-year-old man developed chills, fever, and cough. The findings were non-specific. A roentgenogram showed granulomas and fibrotic changes in both upper lobes. Urine analysis showed albumin $4+$, red and white blood cells, and red-cell casts. Blood urea nitrogen (BUN) concentration was $13.9 \mathrm{mmol} / 1(39 \mathrm{mg} / 100 \mathrm{ml})$ and serum creatinine concentration $327 \mu \mathrm{mol} / 1(3.7 \mathrm{mg} / 100 \mathrm{ml})$. Other laboratory results were negative. Renal failure progressed to oliguria. A lung biopsy specimen showed only fibrosis, while a renal biopsy specimen disclosed increased mesangial matrix, neutrophilic infiltrates, and crescents in seven out of 13 glomeruli. Immunofluorescence staining showed only fibrin in the crescents (figure) ${ }^{1}$. Haemodialysis was instituted thrice weekly. Four months later urinary output increased, and haemodialysis was discontinued when the creatinine clearance was $28 \mathrm{ml} / \mathrm{min}$.

Case 2-A 62-year-old man gave a two-month history of fever and malaise. He had no specific physical findings. Urine analysis showed albumin $4+$ and numerous white and red blood cells. BUN concentration was $11 \cdot 1$ $\mathrm{mmol} / 1(31 \mathrm{mg} / 100 \mathrm{ml})$, creatinine clearance $20 \mathrm{ml} / \mathrm{min}$, and urinary protein excretion $9.8 \mathrm{~g} /$ day. A renal biopsy specimen showed cellular proliferation and crescents in five out of nine glomeruli. Immunofluorescence staining showed focal segmental C3 and generalised fibrin deposits. Thrice-weekly haemodialysis was instituted when the creatinine clearance decreased to $3 \mathrm{ml} / \mathrm{min}$. Fourteen months later the creatinine clearance increased to $18 \mathrm{ml} / \mathrm{min}$ and dialysis was discontinued.

Case 3-A 67-year-old man developed diarrhoea and dark urine. Three months later he presented to the hospital with pulmonary oedema. BUN concentration was $33.6 \mathrm{mmol} / 1(94 \mathrm{mg} / 100 \mathrm{ml})$, serum creatinine concentration was $972 \mu \mathrm{mol} / 1(11 \mathrm{mg} / 100 \mathrm{ml})$, and the patient produced no

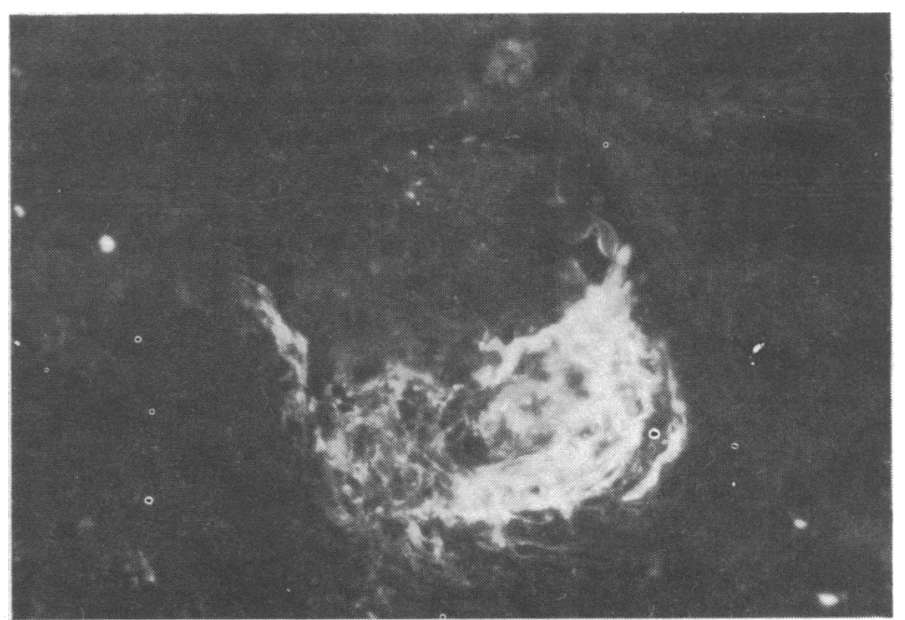

Case 1. Immunofluorescence staining of glomerulus showing sparse staining of capillary loops with fibrin. Crescent is well outlined. $\times 400$ (original magnification).

urine. A specimen showed a necrotising proliferative glomerulonephritis with crescents affecting over half of 30 glomeruli. Immunofluorescence showed sparse deposits of C3 and IgG. Haemodialysis was required for four months, after which the urinary output increased and renal function returned. Dialysis was withdrawn and the creatinine clearance increased to $28 \mathrm{ml} / \mathrm{min}$.

\section{Comment}

Rapidly progressive glomerulonephritis may be classified into three distinct immunofluorescent patterns: type 1 shows diffuse linear IgG staining and is associated with antiglomerular basement membrane antibody; type II shows diffuse granular deposits of $\operatorname{IgG}, \operatorname{IgM}$, and, less often, IgA accompanied by $\mathrm{C} 3$ deposits in the peripheral capillary loops; and type III shows sparse or no deposits of IgG or C $3 .^{5}$

Our patients had idiopathic rapidly progressive glomerulorephritis and type III immunofluorescent patterns. All recovered after several months of haemodialysis without specific treatment, although a beneficial effect of heparin during haemodialysis cannot be excluded. We find that patients with this condition showing type III patterns have a more benign course than those with either type I or type II patterns. ${ }^{1}$ Six of the nine patients with rapidly progressive glomerulonephritis in the series of Bolton and Couser ${ }^{4}$ had no immunofluorescence staining. Those workers prudently suggested a prospective, controlled evaluation of their regimen. We endorse their opinion and raise the possibility that this condition, particularly with no or sparse immunofluorescence staining, may improve spontaneously.

This work was supported by the medical research service of the Veteran Administration. We thank Linda Gladish for secretarial work, and Dr Howard B Davis for referring case 2.

Requests for reprints should be addressed to: Dr Takeshi Ozawa, Renal Section, Veterans Administration Hospital, 1481 West 10th Street, Indianapolis, Indiana 46202, USA.

${ }^{1}$ McLeish, K R, et al, Clinical Nephrology, 1978, 10, 43.

2 Lockwood, C M, et al, Lancet, 1977, 1, 63.

${ }^{3}$ McLeish, K R, et al, Clinical Nephrology, 1978, 10, 71.

4 Bolton, W K, and Couser, C M, American Fournal of Medicine, 1979, 66, 495.

5 Glassock, R J, and Bennett, C M, in The Kidney, ed B M Brenner and F C Rector. Philadelphia, Saunders, 1976.

(Accepted 10 fuly 1979)

Department of Medicine, Indiana University School of Medicine, Indianapolis, Indiana 46223

DOUGLAS R MAXWELL, MD, associate professor of medicine

TAKESHI OZAWA, MD, assistant professor of medicine RICHARD L NIELSEN, MD, fellow in nephrology

FRIEDRICH C LUFT, MD, associate professor of medicine 